\title{
Ventricular Tachycardia
}

National Cancer Institute

\section{Source}

National Cancer Institute. Ventricular Tachycardia. NCI Thesaurus. Code C50802.

A disorder characterized by an electrocardiographic finding of three or more consecutive complexes of ventricular orig in with a rate greater than a certain threshold (100 or 120 beats per minute are commonly used). The QRS complexes are wide and have an abnormal morphology. (CDISC) 